\title{
Citizens Satisfaction with E-Government Mobile Services and M-Health Application during the COVID-19 Pandemic in Al-Madinah Region
}

\author{
Ahad Abdulqader Allam', Amer Nizar AbuAli', Fahad Mahmoud Ghabban1, \\ Omair Ameerbakhsh¹, Ibrahim Mohammed Alfadli' ${ }^{1}$ Abdulaziz Saleh Alraddadi² \\ ${ }^{1}$ College of Computer Science and Engineering, Information System Department, Taibah University, Madina, Saudi Arabia \\ ${ }^{2}$ College of Computer Science and Engineering, Taibah University, Yanbu, Saudi Arabia \\ Email: fghaban@taibahu.edu.sa
}

How to cite this paper: Allam, A. A., AbuAli, A. N., Ghabban, F. M., Ameerbakhsh, O., Alfadli, I. M., \& Alraddadi, A. S. (2021). Citizens Satisfaction with E-Government Mobile Services and M-Health Application during the COVID-19 Pandemic in Al-Madinah Region. Journal of Service Science and Management, 14, 636-650.

https://doi.org/10.4236/jssm.2021.146040

Received: October 13, 2021

Accepted: December 21, 2021

Published: December 24, 2021

Copyright (อ 2021 by author(s) and Scientific Research Publishing Inc. This work is licensed under the Creative Commons Attribution International License (CC BY 4.0). http://creativecommons.org/licenses/by/4.0/

\begin{abstract}
The global COVID-19 pandemic has reactivated the role of e-government. Widespread quarantine restrictions as social distancing and stay-at-home drives to online interaction. The ongoing health crisis has changed how the e-government implements business continuity strategies, provides citizens with vital services, and ensures their satisfaction. The researcher aims to measure the effect of the COVID-19 pandemic on the citizens' satisfaction with the e-government services and Health Care applications in Al-Madinah region. It identifies the factors that facilitate using online government services from the citizens' perspective, and the utilization of e-government services is a way to manage the health crisis. The digital capabilities of the Kingdom of Saudi Arabia, in line with Vision 2030, leverage fifteen years of sustained investment in new digital technology and integrated government platforms. It provides a stable base for the COVID-19 emergency response's vital aspects, including sustained access to multiple e-government resources.
\end{abstract}

\section{Keywords \\ E-Government, M-Health Application, COVID-19 Pandemic, \\ Citizens' Satisfaction, ICT}

\section{Introduction}

In recent years the usage of Information and Communication Technologies (ICTs) has grown substantially, which had a significant effect in making the frequent procedure easier and more effective on various aspects with the increasing growth 
in the use of the internet (Shahiduzzaman et al., 2015). The technological advancement initiates the rise of the Electronic Government (e-government) field. Saudi Arabia's government is continuously seeking to modernize the country's ICT infrastructure are applied it to government processes and practices with the aim of increasing efficiency, transparency, and citizen participation. Electronic Government (e-government) is the use of (ICT) Information and Communication Technology in the government sector to improve productivity, accountability, and public participation and reach a digital maturity level of services in this field (Muzafar \& Jhanjhi, 2020).

The key priorities for implementing the vision 2030 in the program of ambitus nation have effective governance "Vision 2030 is creating a high-performing government that is effective, transparent and accountable. It is empowering citizens, the private sector and non-profits to take the initiative in identifying opportunities for realizing the agenda's objectives" (Vision 2030, 2016). This digital transition initiates the development of e-governments in order to improve the economy of the Kingdom.

Since the early 2020, the global COVID-19 pandemic has reactivated the role of e-government. The accelerated and disturbing spread of the Coronavirus around the world has given urgency to remote transactions, in all fields, including electronic government transactions, financial technology, and electronic payment systems. Widespread quarantine restrictions, social distancing, and stay-at-home drive rise in online interaction (Inkster et al., 2020).

Digital technologies are important for continuing the delivery of services by providing access to information in the time of the crisis. Telework applications, e-education e-health, electronic and telephone payments, and e-commerce shopping have taken shape. Focus on maintaining the efficiency and continuity of the Government services obtained it's important to the national portal. "Yesser" e-government program has played a leading role in providing the services and rising the speed of response. E-Platform of the Ministry of the Interior that enables civilians and residents of Saudi Arabia to use a variety of e-government services. As a result of the lockdown, an increased number of people are using it to access facilities instead of physically visiting administrative support centers. COVID-19 is not obvious, uncertainty can lead to anguish and a sense of helplessness for a lot of people.

This research project examined the effect of the health pandemic from the Citizen side in the terms of Citizen satisfaction of e-government services during the COVID-19 case study of the Al-Madinah Region in Saudi Arabia. Using Technological Acceptance Model (TAM) for measuring the satisfaction of the citizen, ease of use, trust, and usefulness, by conducting quantitively research method using questioner of sample 350 of the citizen of Al-Madinah in various demographic.

\subsection{Research Problem Definition}

The national platform and other m-Health applications were established to man- 
age the crisis and provide e-government services to citizens, residents, and visitors. This research project aimed to determine the effects of the COVID-19 pandemic on citizens' satisfaction with e-government mobile services and m-Health applications by establishing hypotheses based on previous studies measuring citizens' satisfaction using a questionnaire as numerical data collection tool. A quantitative approach was used to explore how the government has used digital technology to enable interactive communication between citizens and government agencies in online service domains during the crisis.

This research project was designed to address the following question: What is the effect of the COVID-19 pandemic on citizens' satisfaction with e-government mobile services and m-Health applications in the Al-Madinah Region?

\subsection{Research Hypotheses}

The researcher established the following hypotheses based on the literature reviewed and the purpose of the study:

- H1: Citizens' trust in the e-government positively affects their satisfaction with e-government mobile services and m-Health applications during COVID-19.

- H2: Citizens' trust in the internet positively affects their satisfaction with egovernment mobile services and m-Health applications during COVID-19.

- H3: The usefulness of the e-government mobile services and m-Health applications positively affects citizens' satisfaction during COVID-19.

- H4: The ease of use of the e-government mobile services and m-Health applications positively affects citizen satisfaction during COVID-19.

\subsection{Significance of Research}

The research highlights the role and effects of the COVID-19 pandemic on citizens' satisfaction using e-government mobile services and the m-Health application in the Al-Madinah region. Few studies have discussed citizens' satisfaction with these applications, let alone during the COVID-19 pandemic. Given the current study, this study is particularly timely as it explains how people interconnect with government mobile services in new and innovative ways. Most prior studies on e-government have been based on its implementation and people's readiness, the factors affecting satisfaction, and the factors restricting citizens' adaption to new technology. Government sectors seek to enhance the quality of their services to ensure citizens and residents are satisfied.

\section{Literature Review}

Information and communication technologies (ICTs) that have been used by government authorities include Wide Area Networks, the Internet, and mobile computing (Almarabeh \& AbuAli, 2010). E-government is a field that emerged in the late 1990s and has been adopted by several countries around the world (Grönlund \& Horan, 2005; Alqahtani, 2016). E-government is defined as the use of ICT and the internet to provide government information and services to 
people. As such, it encompasses the use of databases, networks, and personal identity systems for the benefit of enterprises, workers, individuals, and other stakeholders to communicate and interact with the government through various electronic media (Al-Hujran et al., 2015; Almrezeq et al., 2019). Although scholars and experts have different conceptions of e-government, the majority agreed that government administration, laws, legislation, and frameworks are designed to facilitate service delivery and to coordinate, collaborate, and incorporate internal processes. Mohammad et al. (2009) applied new concepts such as transparency, accountability, and citizen participation to evaluations of e-government performance.

Many developed countries such as the United Kingdom, the United States, Canada, Norway, Germany, and South Korea firmly agreed that they could use emerging web technologies in order to develop more citizen-centered, efficient, and productive governments (Chan et al., 2010). E-Government is being actively deployed around the globe, as demonstrated by the fact that almost every country had created a government website by 2010 (United Nations, 2010).

The government of Saudi Arabia utilizes ICT to deliver e-government services, minimize costs, enhance facilities, save time, and maximize productivity and efficiency across the public sector. The KSA government has initiated the process of adopting a plan for e-government (El-sofany et al., 2012; Al-Mushayt et al., 2012), emphasizing the role of its transformation on and enormous benefits for the national economy. The King has issued several executive orders to the government to implement a number of royal decrees to facilitate e-government functions, including regulations that provide the kingdom's citizens with a multitude of foundational digitization and move to online services. The royal decrees were released in the following ordinances:

- Royal Order Decree No. 7/B/2427 on March 20th, 2003-The Ministry of Finance approved the e-government initiative.

- Royal Decree No. 7/B/33181 enabled the Ministry of Information Technology to introduce e-government policies upon approval from the Executive Government (Yamin \& Mattar, 2016).

In 2005, the Ministry of Communications and Information Technology (MCIT) established Yesser (the Saudi National e-government Project) to emphasize the value of transitioning to the information society and modernizing government administration by implementing services electronically. The Saudi e-government program Yesser consists of three phases to initiate the digital modernization and transformation of government sectors and enhance service delivery. A supervisory committee was set up to actualize the national e-government strategy through the First Action Plan phase, which covered the period from 2006 to 2010 (Yesser, 2006). Based on the First Action Plan's achievements, Yesser produced the Second Action Plan phase, which covered 2012 to 2016 in cooperation with government departments, universities, the private sector, members of the general public, consultancy companies, and foreign consultants. The Second Action Plan was centered on four strategies: creating a sustainable e-government-oriented 
workforce, enhancing the public's experience engaging with the government, fostering a culture of cooperation and creativity, and improving government performance (Yesser, 2012; Alqahtani, 2016).

The execution of these action plans and the work done by individual government departments in conjunction with Yesser has paid dividends. For example, the Kingdom of Saudi Arabia improved its ranking in the United Nations (UN) e-government development index from 80th in 2005 to 35th in 2014 (Yesser, 2012). Vision 2030 is the roadmap for Saudi Arabia to achieve a global ranking among the top G20 countries in terms of its governments' effectiveness and web index (Vision 2030, 2016). The third phase that will be adopted until 2024, Smart Government, has not been announced yet (Yesser, 2020).

Saudi Arabia's government is continuously seeking to modernize the country's ICT infrastructure and reach digital maturity in the e-government field. In 2018, e-government reached a 71 percent maturity level, which was a major improvement from 58 percent in 2016. Vision 2030 has 96 strategic priorities, all of which aim to change individuals' lifestyles based on 13 delivery programs ( $\mathrm{Mu}$ zafar \& Jhanjhi, 2020). The Digital Transition Initiative is one of Vision 2030's key priorities to improve the economy of the Kingdom by creating a dynamic digital society and turning Saudi Arabia into an international strategic ICT center.

The Absher platform was Saudi Arabia's first entry into e-government in 2010. The Ministry of Interior launched a productivity platform for its citizens and foreign residents with the primary objective of helping consumers accomplish their activities more efficiently, whether at home or abroad (Al-Khateeb et al., 2015; Alqahtani, 2016). The Absher portal is becoming more commonly used for the completion of daily tasks (e.g., checking regular addresses, registering cars, e-booking government appointments, and applying for visas has never been simpler for Saudi citizens and residents) (Algarni, 2020).

The world is facing its largest health crisis in decades. Since the beginning of the crisis, measures are taken to mitigate the spread of COVID-19, have caused an unprecedented economic impact on businesses and countries (WHO, 2020). Stringent regulations to halt the spread of the virus in line with Saudi Center of Disease Control (CDC) regulations have been implemented by the Saudi MOH (Ministry of Health), MOE (Ministry of Education), MOI (Ministry of the Interior), and MIA (Ministry of Islamic Affairs) all of which collaborate extremely well. Saudi Arabia was one of the first countries to shift its educational platform to fully online learning. E-government services facilitated various agencies to deliver stable, credible, and client services while ensuring data sharing consistency across e-government systems. The nation was also quick to implement social distancing measures. Many amenities and necessary information were provided to the citizens through e-government media (Abolfotouh et al., 2020) such as Gov.sa, the unified national platform, Absher, and Muqeem. The national platform meets all citizens' needs through a single point with a unified digital iden- 
tity. It maintained citizens' reliable access to several government services when the curfew was applied at the national level (WBG, 2020).

The Yesser e-government program has developed integrated and interoperable business continuity platforms (IDC, 2019). Vision 2030 leveraged 15 years of infrastructure investments in new digital technology and efficient digital government systems to establish a reliable platform for vital components of the COVID-19 emergency response, including greater accessibility to different e-government services (WBG, 2020).

Recognizing the importance of mobile health applications during a crisis, Saudi government officials ensure that safety procedures are followed inside the country, including citizens' adhesion to home quarantine safety protocols. The Minister of Health $(\mathrm{MOH})$ built new safety platforms Mawid, Sehha, Tabaoud, Sehhaty, and Tawakkalna to benefit both users and patients by enabling the government and healthcare providers to assess the extent of the dissemination of COVID-19. In addition to actively tracking the situation, government officials use website portals and mobile applications to educate and update the public.

\section{1. e-Government Mobile Services and Applications}

1) Absher: is an e-Platform of the Ministry of the Interior that enables citizens and residents of Saudi Arabia to use a variety of e-government services access to 200 government services (Algarni, 2020). As a result of the lockdown, an increased number of people are using Absher to access different governmental online channels instead of physically visiting administrative support centers.

2) Najiz: is an integrated services gateway that provides beneficiaries of the Ministry of Justice (including citizens, residents, and businesses) rapid and easy access to all electronic justice services (Najiz, 2020).

3) Muqeem: is the service that offers direct, around-the-clock access to the databases of the General Directorate of Passports so that residents may obtain updated information on all transactions (Muqeem, 2020).

4) Eatamarna: for the first time in history, Saudi Arabia briefly halted travel to its holy sites, one of the most important religious meeting places for Muslims (Finatri et al., 2020; Jokhdar et al., 2021). As a result of the pandemic, application emerged to handle entry to Al-Rawdah and Makkah for prayers and Umrah. Visitors had to be specially granted permission to enter the holy mosques (Parveen, 2020). People were not allowed to book a specific date and time to enter Makkah to perform the Umrah unless they could prove they were not infected and their data related to Tawakkalna.

\subsection{M-Health Application}

Mobile health solutions (m-Health) have captured the attention of health care professionals. Patients with moderate symptoms who test positive for COVID-19 can be monitored using mobile health technology. They are usually advised to self-quarantine at home or to seek care at community treatment centers. The 
government may also apply technologies like artificial intelligence (AI), the global positioning system (GPS), and Bluetooth.

Many of these applications can be used by almost all mobile device users because they are open source, available on Android and IOS, and freely accessible on Google Play and the App Store (Alanzi, 2021; Hidayat-ur-Rehman et al., 2021):

1) Tawakkolna: the Saudi Data and Artificial Intelligence Authority (SDAIA) built the app to displays the health status of household members added to a status card according to the data received from Absher. An interface displays users' health status and helps them receive permits for activities after curfew as well as updates on actions that may breach security measures (Perveen et al., 2020; Alanzi, 2021; Hidayat-ur-Rehman et al., 2021). It is a color-coded scheme that reflects an individual's condition; green means there is no COVID-19, yellow is the suspicion of an infection, and the brown barcode displays an infection for a person who is prohibited to leave home (Alam \& Qamar, 2020). The application promotes transactions between related institutions to minimize the health, economic and social impacts that can arise from not following proper COVID-19 measures. Tawakkalna launched fifteen services in 2020 during the quarantine period to gauge people's awareness and reactions, educate the concerned authorities, and monitor traceability. After the government decided to resume regular activities and remove curfew restrictions, Tawakkalna released twenty-seven new services. The executive manager of Tawakkalna announced in 2021 that new electronic payment features will be added to ensure high-quality services. The continuous updates by SADIA developers have made the application an electronic wallet for personal documents.

2) Tabauod: tracks the distribution of COVID-19 infections and can detect the latest exposure of people who tested positive over the past 14 days while keeping their details private. It allows users to be aware of confirmed cases of COVID-19 in their proximity (Alanzi, 2021).

3) Tetamman: assists in scheduling appointments for COVID-19 examinations, thus providing regular contact and follow-up on patients' cases via daily reports of their symptoms.

4) Sehhaty: provides access to health-related information and the medical care services provided by several different health organizations in Saudi Arabia.

5) Mawid: the Central Appointment System is an online system for confirming appointments with the Ministry of Health and arranging, canceling, or rescheduling appointments at primary health care centers.

6) Sehha: eHealth software is designed to offer patients online consultations with licensed physicians of all specialties.

\section{Research Methodology}

The researcher used a quantitative method in the form of a questionnaire to 
analyze data and gain insights on citizens' satisfaction with e-government mobile services and m-Health applications during COVID-19 in the Al-Madinah region. Theories were tested by gathering sample size data which was then represented and analyzed through statistics and graphs. The proposed model used in this study was a formulation of (Davis, 1989) TAM factors, PEOU and PU, and the trustworthiness constructs. The study tested whether each of the three variables had a positive effect on satisfaction as well as the existence of a relationship between usefulness and ease of use. Researcher obtained data from citizens who use e-government mobile services and $\mathrm{m}$-Health applications by creating and distributing an online self-administered questionnaire. Using Google Forms made the obtention of the sample accurate and consistent. Online survey was chosen as the most cost-effective and confidential approach because the findings could not be traced back to individual respondents. The questionnaire was written in English and translated into Arabic to eliminate any potential language barriers. The measurements of the research variables were selected and adopted using a 5 -point Likert-type scale, the most commonly used instrument for measuring affective variables.

The questionnaire collected 524 responses -174 were used in the pilot survey to measure the validity of the questionnaire. 350 individuals of varying nationalities (both citizens and residents) comprised the sample study for the Al-Madinah Region. The reliability analysis was performed on the pilot study results and revealed that Cronbach's alpha values exceeded the recommended value of 0.7 (ranging between 0.805 and 0.974 for $n=174$ ). Data collected from the questionnaire were introduced in a basic Microsoft Excel program and then converted for use in SPSS software.

\section{Research Design and Model}

Technology acceptance model (TAM) remains the most widely-used theoretical model in the domain. The perceived usefulness is affected by perceived ease of use, while both beliefs are dictated by external variables such as trust, satisfaction, gender, and age, etc. This study analyzes citizen satisfaction with e-government services and Health Application during COVID-19.

\section{Research Construct}

In order to assess the satisfaction using the Technology Acceptance ModelTAM, to determine the factors that affect the citizen satisfaction with e-government services and Healthcare Application in the complexities of the phenomenon of the COVID-19 pandemic, by finding the relationships between the variables: trust, usefulness, ease of use, and satisfaction, where the study tests if each of the three variables has a positive effect on satisfaction, besides testing the existence of a relationship between usefulness and ease of use as the original variables of Technology Acceptance Model (TAM). Figure 1 presents the proposed model of this study. 


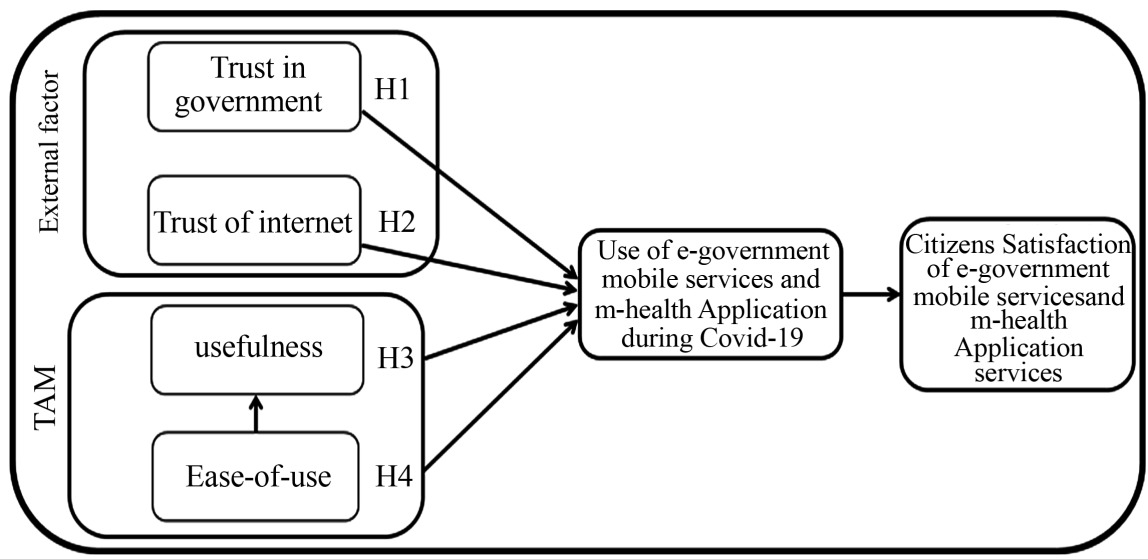

Figure 1. Proposed model.

\section{Results of the Questionnaire}

This section presents the results of the questionnaire which the researchers used in this study.

Table 1 and Table 2 show the main results.

\section{Data Analysis}

Statistical terms of measure are particularly valuable for summarizing study and outcome variables the validity of internal accuracy, internal reliability, results were done first in order to find variables to be included in the study hypotheses, and then Cronbach's $(\alpha)$ and Pearson's correlation coefficients of each of those variables were used to investigate the variables' relationship to support each of the study hypotheses.

In quantitative studies, validity examines whether the data is valid by testing if the data is set to measure what it is intended to measure (Mohajan, 2017). The validity of the research instrument was also verified by conducting an exploratory factor analysis and first and second-order confirmatory factor analysis (Sablan, 2019), to assess the factorability of the data the KMO and Bartlett tests were employed. A KMO value of 0.60 and higher is considered good (Field, 2013). The findings are: $\mathrm{KMO}=0.885$; Bartlett test: $\mathrm{v} 2=4174.090, \mathrm{df}=300(p=$ 0.0001 ), which indicates the factorability of the Instrument. Table 3 shows the results of KMO and Bartlett's Test.

An exploratory factor analysis (EFA) was computed, and the Varimax rotation method was used to establish the links between the observed variables the number of factors was determined using the Kaiser criterion and the Scree test and eigenvalues of factors equal or superior to one were considered (Biasutti \& Frate, 2017). The EFA revealed a structure of five factors, the rotated component matrix indicated values ranging between 0.542 and 0.966 , when an item was loaded in two factors, the higher value was considered. The total variance explained by the factors is $76.508 \%$ as reported. Table 4 shows the percentage of variance, total loading for every factor for the instrument. 
Table 1. Questionnaire main results.

\begin{tabular}{cccc}
\hline \multirow{2}{*}{ Gender } & Male & Responses & $\%$ \\
\hline \multirow{2}{*}{ Citizenship } & Female & 157 & 44.9 \\
& Citizen & 193 & 55.1 \\
\hline \multirow{2}{*}{ Lducation } & Resident & 295 & 84.3 \\
& High School & 14 & 4 \\
& Diploma & 41 & 11.7 \\
\hline Bachelor's degree & Master Degree & 45 & 12.9 \\
& Ph.D & 15 & 4.3 \\
& Students & 75 & 52.6 \\
& employed & 31 & 21.4 \\
& unemployed & 84 & 24 \\
\hline & Retired & 74 & 46 \\
\hline
\end{tabular}

Table 2. Health application.

\begin{tabular}{ccc}
\hline Application & Responses & $\%$ \\
\hline Najiz & 87 & $24.85 \%$ \\
Tawakkalna & 343 & $98 \%$ \\
Mawid & 196 & $56 \%$ \\
Tabaud & 155 & $44.285 \%$ \\
Absher & 298 & $85.142 \%$ \\
Muqeem & 42 & $12 \%$ \\
Tetamman & 106 & $30.285 \%$ \\
Eatemmarna & 192 & $54.857 \%$ \\
Sehhaty & 217 & $62 \%$ \\
Sehha & 124 & $35.428 \%$ \\
\hline
\end{tabular}

Table 3. KMO and Bartlett's test.

\begin{tabular}{lcc}
\hline \multicolumn{2}{c}{ Kaiser-Meyer-Olkin Measure of Sampling Adequacy } & 0.885 \\
& Approx. Chi-Square & 4174.090 \\
Bartlett's Test of Sphericity & Df & 300 \\
& Sig. & 0.000 \\
\hline
\end{tabular}


Table 4. Percentage of variance, total loading for every factor for the instrument.

\begin{tabular}{ccc}
\hline \multirow{2}{*}{ Component } & \multicolumn{2}{c}{ Extraction Sum of Squared Loading } \\
\cline { 2 - 3 } & Total Loading & \% of Variance \\
\hline Satisfaction & 9.316 & 37.265 \\
Trust in the Internet & 3.659 & 14.634 \\
Trust in e-Government & 2.588 & 10.351 \\
Usefulness & 2.296 & 9.186 \\
Ease of use & 1.268 & 5.072 \\
\hline
\end{tabular}

Reliability of the questionnaire has also been checked using Alpha Cronbach coefficient and split-half coefficients. The split-half reliability method requires dividing up the variables' items into two parts and calculating correlations between the first half and the second half of each variable's items. The Spearman correlation test was used to estimate the correlation between the variables. Table 5 shows Alpha Cronbach and Split-Half Coefficients.

\section{Results}

The researcher tries to determine if any of the four independent variables could be incorporated into the model. One of the initial steps was to see whether any of the four variables (Trust of Internet, Trust in Government, Usefulness, Easeof-Use) could perhaps indicate satisfaction as a dependent variable. However, in the Stepwise regression method, SPSS calculates only significant predictors and automatically excludes non-significant variables. In this case, usefulness has been excluded since it was a non-significant predictor.

Table 6 reveals that there are three Models to predict Satisfaction, the first model determines that usefulness can be a predictor of satisfaction, where the value of $\mathrm{F}$ (654.306) is significant at the level of significance 0.001 , and Its value of $t$ are 25.579, which is also significant at the level of significance 0.001 .

Moreover, the percentage of contribution of usefulness to predict satisfaction is approximately $65.2 \%$. The value of $\mathrm{B}$ is 1.118 , from Table 6 we can write the following equation:

$$
\text { Satisfaction }=6.230+1.118 \text { Usefulness }
$$

The second model demonstrates that usefulness and ease-of-use can be predictors of satisfaction, where the value of F (396.636) is significant at the level of significance 0.001 , and Its value of $t$ is $12.623,6.993$, which is also significant at the level of significance 0.001 . Moreover, the percentage of contribution of usefulness and ease-of-use to predict satisfaction is approximately $69.4 \%$. The value of $\mathrm{B}$ is $0.789,0.448$, from Table 6 . We can write the following equation:

$$
\text { Satisfaction }=6.230+0.789 \text { Usefulness }+0.448 \text { ease-of-use }
$$

The third model demonstrates that usefulness and ease-of-use and trust in e-government can be predictors of satisfaction, where the value of F (299.563) is 
Table 5. Alpha Cronbach and split-half coefficients.

\begin{tabular}{lccccc}
\hline & & & \multicolumn{2}{c}{ Split-half Reliability Coefficients } \\
\cline { 5 - 6 } & Variables & $\begin{array}{c}\text { Cronbach's } \\
\text { Alpha }\end{array}$ & $\begin{array}{c}\text { Correlation } \\
\text { Coefficient }\end{array}$ & $\begin{array}{c}\text { Sength Corrections } \\
\text { Spearman-Brown } \\
\text { Coefficient }\end{array}$ & $\begin{array}{c}\text { Guttman } \\
\text { Coefficient }\end{array}$ \\
\hline \multirow{2}{*}{ Trust } & Trust in & 0.869 & 0.745 & 0.858 & 0.840 \\
\cline { 5 - 6 } & $\begin{array}{c}\text { e-government } \\
\text { Trust in the Internet }\end{array}$ & 0.974 & 0.944 & 0.971 & 0.971 \\
\hline \multirow{2}{*}{ TAM } & Usefulness & 0.892 & 0.769 & 0.873 & 0.790 \\
\cline { 4 - 6 } & Ease of use & 0.805 & 0.692 & 0.818 & 0.808 \\
\hline
\end{tabular}

Table 6. Multiple regression analysis between trust of internet, trust in government, usefulness, ease-of-use, and satisfaction $(\mathrm{N}=350)$.

\begin{tabular}{|c|c|c|c|c|c|c|c|}
\hline Dependent & Model & Independent & $\mathrm{R}$ & $\begin{array}{c}\mathrm{R} \\
\text { Square }\end{array}$ & B & Beta & $\mathrm{t}$ \\
\hline \multirow{9}{*}{ Satisfaction } & \multirow{2}{*}{ Model One } & (Constant) & \multirow{2}{*}{0.808} & \multirow{2}{*}{0.653} & 6.230 & - & $6.389^{\star *}$ \\
\hline & & Usefulness & & & 1.118 & 0.808 & $25.579^{\star *}$ \\
\hline & \multirow{3}{*}{ Model Two } & (Constant) & \multirow{3}{*}{0.834} & \multirow{3}{*}{0.696} & 5.759 & - & $6.282^{\star *}$ \\
\hline & & Usefulness & & & 0.789 & 0.570 & $12.623^{\star *}$ \\
\hline & & ease.of.use & & & 0.448 & 0.316 & $6.993^{* *}$ \\
\hline & \multirow{4}{*}{ Model Three } & (Constant) & \multirow{4}{*}{0.850} & \multirow{4}{*}{0.722} & 1.349 & - & 1.155 \\
\hline & & Usefulness & & & 0.669 & 0.484 & $10.571^{\star *}$ \\
\hline & & ease.of.use & & & 0.373 & 0.263 & $5.951^{\star *}$ \\
\hline & & e.trust & & & 0.356 & 0.208 & $5.725^{\star \star}$ \\
\hline
\end{tabular}

significant at the level of significance 0.001 , and Its value of $t$ are 10.571, 5.951, 5.725 , which is also significant at the level of significance 0.001 . Moreover, the percentage of contribution of usefulness, ease-of-use, and trust in e-government to predict satisfaction is approximately $72 \%$. The value of $B$ is $0.669,0.373,0.356$, from Table 6 we can write the following equation:

Satisfaction $=0.669$ Usefulness +0.373 ease-of-use +0.356 trust in e-government

\section{Conclusion}

In Saudi Arabia, the use of e-government has gained considerable ground and will continue to grow. appraised the significance of government to assess the effect of COVID-19 has reactivated the role of e-government as large as the key role in modernizing and automating governments, particularly when it comes to computing, developing information, and serving citizens. The consequences of the health pandemic, as well as the responsibility of the government to protect 
the general public throughout the duration of the pandemic, will be an important activity to perform in the current health crisis, and also will be performed even after the epidemic is over the end. Absher, Najez, Muqeem, E'tamarna, Tawakklanah, and the Application released from Minister of Health to deal with COVID-19 by releasing innovative services.

The researcher has identified the following conclusions. The growth in demand for online government services is strong, and so is recognition of the need for these online services. The use of electronic government is advancing transactions quickly and efficiently. Better and less time-consuming government operations as a result of using e-government. A growing majority of people agree that using e-government is secure. Electronic administration has now been too advanced that governments cannot continue to ignore. Now the public has the requirement of quality and comfort in obtaining government services; e-government fulfills this desire. Now governments worldwide can no longer continue to disregard e-government. Saudi Arabia must keep pace with new and improved technologies and measure the overall citizen satisfaction of e-government.

Given the significant challenges that m-Government services face in Saudi Arabia, such as being unknown to and underutilized by public people, one of the most significant contributions of this study is to recognize and understand the primary factors that encourage and impede the adoption and diffusion of $\mathrm{m}$ government services as viewed by Al-Madinah citizens. To ensure public satisfaction, the government should maintain the ease of accessing and using these facilities and improve their Consideration of the factors found in this study has the potential to dramatically increase Al-Madinah citizen's perception of technology acceptance of e-government services and healthcare Application, resulting in more active adoption of these services superiority.

\section{Conflicts of Interest}

The authors declare no conflicts of interest regarding the publication of this paper.

\section{References}

Abolfotouh, M. A., Almutairi, A. F., Ala'a, A. B., \& Hussein, M. A. (2020). Perception and Attitude of Healthcare Workers in Saudi Arabia with Regard to Covid-19 Pandemic and Potential Associated Predictors. BMC Infectious Diseases, 20, Article No. 719. https://doi.org/10.1186/s12879-020-05443-3

Alam, T., \& Qamar, S. (2020). Coronavirus Disease (COVID-19): Reviews, Applications, and Current Status. Jurnal Informatika Universitas Pamulang, 5, 213-219. https://doi.org/10.32493/informatika.v5i3.6563

Alanzi, T. (2021). A Review of Mobile Applications Available in the App and Google Play Stores Used during the COVID-19 Outbreak. Journal of Multidisciplinary Healthcare, 14, 45-57. https://doi.org/10.2147/JMDH.S285014

Algarni, H. A. Z. (2020). Using the Technology Acceptance Model (Tam) in Examining Absher System Accpetance in the Kingdom Saudi Arabia. European Journal of Economic and Financial Research, 4, 59-77. 
Al-Hujran, O., Al-Debei, M. M., Chatfield, A., \& Migdadi, M. (2015). The Imperative of Influencing Citizen Attitude toward E-Government Adoption and Use. Computers in Human Behavior, 53, 189-203. https://doi.org/10.1016/j.chb.2015.06.025

Al-Khateeb, A., Faloudah, A., Bahumayd, M., \& Zafar, A. (2015). E-Government Strategy and Its Impact on Economic Development of the Nation: A Case Study of the KSA. E-Government, 2, 105-110. https://doi.org/10.17148/IARJSET.2015.2522

Almarabeh, T., \& AbuAli, A. (2010). A General Framework for E-Government: Definition Maturity Challenges, Opportunities, and Success. European Journal of Scientific Research, 39, 29-42.

Almrezeq, N., Alhamdan, R., Mahyub, M., \& Alfayad, M. (2019). An Exploratory Study to Investigate Citizens' Experience with E-Government Mobile Services in Saudi Arabia. 2019 5th International Conference on Information Management (ICIM), 188-196.

Al-Mushayt, O. S., Perwej, Y., \& Haq, K. (2012). Electronic-Government in Saudi Arabia: A Positive Revolution in the Peninsula. ArXiv Preprint ArXiv:1205.3986.

Alqahtani, F. N. (2016). Identifying the Critical Factors That Impact on the Development of Electronic Government using TOE Framework in Saudi E-Government Context: A Thematic Analysis.

Biasutti, M., \& Frate, S. (2017). A Validity and Reliability Study of the Attitudes toward Sustainable Development Scale. Environmental Education Research, 23, 214-230. https://doi.org/10.1080/13504622.2016.1146660

Chan, F. K. Y., Thong, J. Y. L., Venkatesh, V., Brown, S. A., Hu, P. J. H., \& Tam, K. Y. (2010). Modeling Citizen Satisfaction with Mandatory Adoption of an E-Government Technology. Journal of the Association for Information Systems, 11, 519-549. https://doi.org/10.17705/1jais.00239

Davis, F. D. (1989). Perceived Usefulness, Perceived Ease of Use, and User Acceptance of Information Technology. MIS Quarterly, 13, 319-340. https://doi.org/10.2307/249008

El-Sofany, H. F., Al-Tourki, T., Al-Howimel, H., \& Al-Sadoon, A. (2012). E-Government in Saudi Arabia: Barriers, Challenges and Its Role of Development. International Journal of Computer Applications, 48, 16-22. https://doi.org/10.5120/7344-0119

Field, A. (2013). Discovering Statistics Using IBM SPSS Statistics. SAGE.

Finatri, I., Pono, M., \& Jusni, J. (2020). Effect Covid-19: Loyalty of Prospective Umrah Pilgrims to Umrah and Hajj Travel Companies. Hasanuddin Journal of Business Strategy, 2, 31-37. https://doi.org/10.26487/hjbs.v2i3.353

Grönlund, Å., \& Horan, T. A. (2005). Introducing E-Gov: History, Definitions, and Issues. Communications of the Association for Information Systems, 15, 39. https://doi.org/10.17705/1CAIS.01539

Hidayat-ur-Rehman, I., Ahmad, A., Ahmed, M., \& Alam, A. (2021). Mobile Applications to Fight against COVID-19 Pandemic: The Case of Saudi Arabia. Tem Journal-Technology Education Management Informatics, 10, 69-77. https://doi.org/10.18421/TEM101-09

IDC (International Data Corporation) (2019). A Digital Government Vision for the Kingdom of Saudi Arabia. A Report by IDC. International Data Corporation. http://www.idcdigigovreport.com/

Inkster, B., O’Brien, R., Selby, E., Joshi, S., Subramanian, V., Kadaba, M., Schroeder, K., Godson, S., Comley, K., \& Vollmer, S. J. (2020). Digital Health Management during and beyond the COVID-19 Pandemic: Opportunities, Barriers, and Recommendations. JMIR Mental Health, 7, Article ID: e19246. https://doi.org/10.2196/19246

Jokhdar, H., Khan, A., Asiri, S., Motair, W., Assiri, A., \& Alabdulaali, M. (2021). COVID-19 Mitigation Plans during Hajj 2020: A Success Story of Zero Cases. Health Security, 19, 
133-139. https://doi.org/10.1089/hs.2020.0144

Mohajan, H. K. (2017). Two Criteria for Good Measurements in Research: Validity and Reliability. Annals of Spiru Haret University, Economic Series, 17, 59-82. https://doi.org/10.26458/1746

Mohammad, H., Almarabeh, T., \& Ali, A. A. (2009). E-Government in Jordan. European Journal of Scientific Research, 35, 188-197.

Muqeem (2020). https://www.elm.sa/en/e-services/pages/muqeem.aspx

Muzafar, S., \& Jhanjhi, N. Z. (2020). Success Stories of ICT Implementation in Saudi Arabia. In V. Ponnusamy, K. Rafique, \& N. Zaman (Eds.), Employing Recent Technologies for Improved Digital Governance (pp. 151-163). IGI Global.

https://doi.org/10.4018/978-1-7998-1851-9.ch008

Najiz (2020). https://najiz.sa/applications/landing/services

Parveen, M. (2020). Challenges Faced by Pandemic Covid 19 Crisis: A Case Study in Saudi Arabia. Challenge, 63, 349-364. https://doi.org/10.1080/05775132.2020.1822659

Perveen, S., Orfali, R., Ul Azam, M. S., Aati, H. Y., Bukhari, K., Bukhari, S. I., \& Al-Taweel, A. (2020). Coronavirus nCOVID-19: A Pandemic Disease and the Saudi Precautions. Saudi Pharmaceutical Journal, 28, 888-897. https://doi.org/10.1016/j.jsps.2020.06.006

Sablan, J. R. (2019). Can You Really Measure That? Combining Critical Race Theory and Quantitative Methods. American Educational Research Journal, 56, 178-203. https://doi.org/10.3102/0002831218798325

Shahiduzzaman, M., Layton, A., \& Alam, K. (2015). On the Contribution of Information and Communication Technology to Productivity Growth in Australia. Economic Change and Restructuring, 48, 281-304. https://doi.org/10.1007/s10644-015-9171-9

United Nations (2010). United Nations E-Government Survey 2010. Leveraginge-Government at a Time of Financial and Economic Crisis. https://doi.org/10.18356/0e749d15-en

Vision 2030, G. (2016). Government of Saudi Arabia. Saudi Government. https://www.vision2030.gov.sa/

WBG (The World Bank Group) (2020). Unlocking the Digital Era during the Lock Down, Covid-19 Digital Response and Future of Digital Government in KSA. The World Bank Group.

WHO (World Health Organization) (2020). Global Collaboration to Accelerate New COVID-19 Health Technologies.

https://www.who.int/ar/emergencies/diseases/novel-coronavirus-2019

Yamin, M., \& Mattar, R. (2016). E-Government in Saudi Arabia-An Empirical Study. BVICA M's International Journal of Information Technology, 8, 944.

Yesser (2006). The National E-Government Strategy and Action Plan YESSER 2006-2010. https://www.yesser.gov.sa/en

Yesser (2012). National E-Government Action Plan. Second National e-Government Action Plan for Kingdom of Saudi Arabia 2016-2012. https://www.yesser.gov.sa/en.

Yesser (2020). Guide Manual for Technical Procedures upon Return to Work, after the Corona Pandemic in Government Agencies. https://www.yesser.gov.sa/en 